\title{
A CUATRO AÑOS DE CRISIS MUNDIAL CONTINÚAN SERIOS NUBARRONES
}

\author{
TO FOUR YEARS AGO OF WORLD CRISIS, \\ THE DARK CLOUDS ARE STILL THERE
}

\author{
Beatriz Herrera García * \\ Docente Principal de la Facultad de Ciencias Contables \\ Universidad Nacional Mayor de San Marcos-UNMSM \\ Lima-Perú
}

[Recepción: Setiembre de 2012/ Conformidad: Octubre 2012]

\section{RESUMEN}

Al finalizar el tercer trimestre de 2012, la situación de la economía mundial sigue siendo un reto, con mayor riesgo de una recesión severa. Cuatro grandes debilidades de la economía mundial siguen conspirando contra una robusta recuperación económica en las economías desarrolladas, creando un círculo vicioso:

i) El desapalancamiento de los bancos, las empresas y los hogares sigue limitando los flujos normales de crédito y de consumo, así como, la de demanda de inversión;

ii) El desempleo sigue siendo alto, una condición que es a la vez causa y efecto en la prevención de la recuperación económica;

iii) Las respuestas de austeridad fiscal a las crecientes deudas soberanas desalientan el crecimiento económico y un retorno a la sostenibilidad de la deuda de todos, haciendo todo más difícil, y

iv) Las exposiciones bancarias y la deuda soberana perpetúan la fragilidad del sector financiero, y refuerzan el despalancamiento continuado.

\section{Palabras Clave:}

Crisis financiera, crisis económica, desempleo y austeridad fiscal.

\section{ABSTRACT}

At the end of the third quarter of 2012, the global economic situation remains a challenge, with increased risk of a severe recession. Four major weaknesses of the global economy continue to plot against a robust economic recovery in developed economies, creating a vicious circle:

i) The deleveraging of banks, companies and households continue to constrain normal credit flows and consumption as well as investment demand;

ii) Unemployment remains high, a condition that is both cause and effect in the prevention of economic recovery;

iii) fiscal austerity responses to growing sovereign debt discourage economic growth and a return to debt sustainability of all, making everything more difficult, and

iv) The banks exposures and sovereign debt perpetuate the fragility of the financial sector, and reinforce the continued deleveraging.

\section{Keywords:}

Financial crisis, economic crisis, unemployed, tax austerity.

* Doctora en Ciencias Económicas. Ex- Vicerrectora Administrativa- UNMSM. Docente Investigadora de la UNMSM. E- mail: bherrerag@unmsm.edu.pe 


\section{PANORAMA GLOBAL ${ }^{1}$}

A cuatro años de crisis económica y financiera las economías desarrolladas se encuentran estabilizadas en una situación de deuda soberana, en condiciones de bajo crecimiento económico y grave solvencia de algunos países $^{2}$ para hacer frente a sus compromisos de pago. Esto originó el peligro probable de una salida desordenada de la crisis, situación en que los países se verían forzados a hacerse cargo de las pérdidas de sus sistemas financieros ante una declaración de insolvencia de algún país de la zona del euro ${ }^{3}$.

Este panorama sombrío es debido a las recientes perspectivas para el crecimiento económico mundial, situación definida por algunos especialistas, quienes consideran que la economía mundial se tambalea o está al borde de otra crisis importante. Un signo de ello es que el crecimiento mundial de la producción se ha desacelerado considerablemente a partir y durante 2011; para el periodo 2012-2013 se prevé un crecimiento reducido (será un crecimiento anémico).

Efectivamente, el crecimiento económico global empezó a desacelerarse en un amplio frente, comenzó a mediados de 2011 y redujo el ritmo anual de crecimiento a sólo 2.8 por ciento, muy por debajo del último año y que es inferior al ritmo de crecimiento promedio anterior a la crisis mundial. La persistencia del alto nivel de desempleo en Estados Unidos y el bajo crecimiento de los salarios están frenando la demanda agregada $y$, junto a las perspectivas de precios de las viviendas, hace configurar mayores riesgos de una nueva ola de ejecuciones hipotecarias.
El crecimiento en la zona euro se ha desacelerado considerablemente desde principios de 2011, por lo que la crisis de la deuda soberana (cada vez más latente) pesa fuertemente sobre la confianza de los consumidores y empresas en toda Europa.

El fracaso de las políticas en los países en desarrollo para enfrentar el desempleo y evitar los problemas de deuda soberana y, la fragilidad del sector financiero, ha planteado el riesgo más grave para la economía mundial en el corto plazo, con la consideración de una nueva recesión global como una posibilidad real.

Sin embargo, se espera que los países en desarrollo y las economías en transición (anteriormente economías socialistas), continúen creciendo para seguir alimentando el motor de la economía mundial. Con un crecimiento promedio sostenido y una tasa de 5.4 por ciento en 2012 y una tasa de 5.8 por ciento en 2013 pueden lograr ese objetivo.

De los principales países en desarrollo se espera un crecimiento sostenido a pesar de las dificultades recientes. Así, el crecimiento de China e India se han mantenido fuertes, por ejemplo, el crecimiento del producto interno bruto (PIB) en China se desaceleró de una tasa de 10.3 por ciento en 2010 a una tasa de 9.3 por ciento en 2011 y, se prevé continúe disminuyendo por debajo del 9.0 por ciento en el periodo 2012-2013. La economía de India se espera crezca en dicho periodo entre una tasa de 7.7 por ciento y una tasa de 7.9 por ciento, estos estimados están por debajo de la taza lograda en 2010 ( $8.5 \%$ ).

Bajo este contexto, existe un abanico de posibilidades de políticas a implementarse que podrían evitar una doble recesión (recaída), incluyendo:

\footnotetext{
1 El presente artículo es complementario al anterior intitulado: "CRISIS. PERSPECTIVAS DEL EMPLEO Y COMERCIO", ambos corresponden a investigaciones acerca de la coyuntura internacional

2 Grecia, Irlanda, España, Portugal e Italia.

3 El significado de ello es que se agregaría a la crisis de la deuda pública una crisis bancaria.
} 
- el diseño óptimo de políticas fiscales para estimular más directamente la creación de empleo y la inversión en infraestructura;

- la eficiencia energética y el suministro de energías sostenible y la seguridad alimentaria;

- la implementación de consistentes redes de seguridad financiera, una mejor coordinación entre las políticas fiscal y monetaria; y

- la provisión de apoyo suficiente a los países en desarrollo para hacer frente a las consecuencias de la crisis y la coordinación de las medidas de políticas a nivel internacional.

Mientras tanto, se observa que el reto más urgente es la crisis del desempleo aunado a la disminución del crecimiento económico en las economías más desarrolladas que están sufriendo los rezagos de una crisis financiera mundial que estalló en 2008. Posteriormente, la crisis de los bancos privados y el aumento del desempleo debilita las finanzas públicas y la actividad económica, hundiendo a las economías vulnerables en las crisis de deuda soberana. La crisis de la deuda soberana que se inició en 2010, en una serie de países europeos, empeoró durante el segundo semestre de 2011 y agravó la debilidad de los balances financieros de los bancos que dificultó una restructuración ordenada de la deuda soberana, agravando la turbulencia de los mercados financieros.

\section{LAS PERSPECTIVAS DE CRECIMIENTO EN LAS DIVERSAS REGIONES}

La economía mundial, según diversos estudios (FMI, BM, ONU), se encuentra al bor- de de volver a caer en una nueva recesión. Es decir, si se fracasa en las soluciones de políticas en Europa y Estados Unidos ${ }^{4}$, de las crisis del empleo y de la agravación de los problemas de deuda soberana y de la fragilidad del sector financiero, todo esto representaría el mayor riesgo para las perspectivas de la economía global en 2013. Ello sería debido al estado en que se encuentran las economías desarrolladas, al borde de una espiral descendente impulsada por cuatro factores de debilidad que se alimentan mutuamente, estas son: crisis de la deuda soberana; sectores bancarios frágiles; débil demanda agregada con altas tasas de desempleo; y parálisis política causada por entramados políticos y deficiencias institucionales. Estas cuatro grandes debilidades están presentes ya, sin embargo, un mayor deterioro de ellas podría desencadenar un círculo viciosos que conduzca a una grave turbulencia financiera y recesión económica.

La ralentización del crecimiento en las economías desarrolladas está afectando también a las economías emergentes ${ }^{5}$ y en desarrollo. Debido a la débil demanda en los países en desarrollo y a una desaceleración de la economía china, es probable sea afectado el crecimiento económico en Asia Oriental. Después de la desaceleración de 9.2 por ciento en 2010 a 7.1 por ciento en 2011, el crecimiento promedio de Asia Oriental se espera disminuya a más de 6.5 por ciento en 2012. Para 2013, se proyecta un ritmo de crecimiento con un ligero repunte a medida que la demanda mundial se recupere, el PIB de esa región aumentaría un 6.9 por ciento. Por su parte, la desaceleración del crecimiento en Asia del Este, refleja una menor demanda

4 Las altas tasas de desempleo en Estados Unidos, alrededor de 9.0 por ciento, y el bajo crecimiento de los salarios erosionan la demanda agregada, sumándose a las perspectivas de una prolongada alza de los precios de las viviendas que conllevaría renovados riesgos de moratoria del pago de hipotecas. Por su parte, Alemania y Francia, las mayores economías de la eurozona, se acercarían peligrosamente a niveles recesivos mientras que las economías de la periferia europea experimentarían recesiones prolongadas.

5 Las principales economías emergentes del mundo son Brasil, Rusia, India y China (BRIC). 
de importaciones en los países en desarrollo, un aumento de la incertidumbre global y los efectos retardados de la restricción del crédito en algunas partes de las regiones más importantes de China ${ }^{6}$. Asimismo, un crecimiento más débil de las exportaciones y las inversiones en toda la región, se espera sea compensado en parte por la demanda interna (consumo de las familias y consumo del gobierno), como por una política fiscal ligeramente más expansiva. El consumo de los hogares contará con el apoyo persistente de las bajas tasas de interés reales y el aumento de los salarios reales. Se espera, también, los mercados laborales sean razonablemente robustos a pesar del lento crecimiento del empleo, especialmente en el sector manufacturero.

La desaceleración de la inflación se explica principalmente por una disminución de los precios de los alimentos y de los productos básicos, que pueden atribuirse a la mejora de las condiciones de suministro en la región $y$ al debilitamiento del medio ambiente económico mundial. Mientras que varios bancos centrales, incluido el Banco Popular de China (BPCH), aflojaron las condiciones monetarias en respuesta a la menor presión inflacionaria y la desaceleración del crecimiento interno, por lo que no se esperan cambios significativos en la orientación de la política actual durante el resto de 2012.

Por su parte, en el crecimiento económico de América Latina se prevé, también, una desaceleración de 4.3 por ciento en 2011 a 3.7 por ciento en 2012, y luego, una breve aceleración de 4.2 por ciento en 2013. En muchos países de la región, las medidas de estímulo fiscales y monetarias se eliminaron progresivamente frenando el crecimiento de la demanda interna.

México y Brasil experimentarían probablemente desaceleraciones más marcadas. Se prevé una desaceleración del crecimiento económico mexicano a una tasa de 2.5 por ciento en 2012, luego de haber registrado tasas de crecimiento de 5.5 por ciento en 2010 y 3.8 por ciento en 2011. Algo que podría cambiar estos resultados sería un crecimiento algo más fuerte de la economía de Estados Unidos que fortalecería la demanda en las industrias del turismo y las otras exportaciones (no tradicionales), así como, un incremento de las remesas.

En relación al crecimiento económico en Brasil se espera siga disminuyendo luego de haber alcanzado una fuerte recuperación en 2010 con una tasa de 7.5 por ciento para caer a una tasa de 3.7 por ciento en 2011 , por lo que se prevé un enfriamiento aún mayor en 2012, en la que la tasa de crecimiento se podría situar en 2.7 por ciento.

Los pronósticos cuantitativos para el crecimiento de la producción y el comercio mundial para 2012 y 2013 son:

Los economistas del Departamento de Asuntos Económicos y Sociales (UN/ DESA), consideran que en el 2013 pueden presentarse hasta tres escenarios para el crecimiento del producto mundial. Un escenario base (ver, Cuadro 1) en la cuál se estima un crecimiento de 3.2 por ciento. Un escenario optimista que considera un crecimiento de 4.0 por ciento. $Y$ un escenario pesimista que considera un crecimiento de 2.2 por ciento. Todo dependerá de la coordinación internacional de políticas y de la evolución de la crisis de la deuda soberana.

6 Se estima que el crecimiento de China e India sigan siendo vigorosos. El crecimiento del PIB de China se desaceleró de 10.3 por ciento en 2010 a 9.3 por ciento en 2011 y se prevé que se sitúe un poco por debajo de 9.0 por ciento en 2012 y 2013. La economía de India podría crecer a tasas de 7.7 y 7.9 por ciento en estos dos años, tasas levemente inferiores al 8.5 por ciento logrados en 2010. 


\section{Cuadro 1}

Producto y Comercio Mundial, 2009 - 2013

(Cambio porcentual anual)

\begin{tabular}{|c|c|c|c|c|c|}
\hline & 2009 & 2010 & 2011 & 2012 & 2013 \\
\hline Mundo & -2.4 & 4.0 & 2.8 & 2.6 & 3.2 \\
\hline Economías desarrolladas & -4.0 & 2.7 & 1.3 & 1.3 & 1.9 \\
\hline EE.UU. & -3.5 & 3.0 & 1.7 & 1.5 & 2.0 \\
\hline Japón & -6.3 & 4.0 & -0.5 & 2.0 & 2.0 \\
\hline Unión Europea & -4.3 & 2.0 & 1.6 & 0.7 & 1.7 \\
\hline Economías en transición & -6.6 & 4.1 & 4.1 & 3.9 & 4.1 \\
\hline Economías en desarrollo & 2.4 & 7.5 & 6.0 & 5.6 & 5.9 \\
\hline Partida informativa & & & & & \\
\hline Comercio Mundial & -9.9 & 12.8 & 6.6 & 4.4 & 5.7 \\
\hline
\end{tabular}

FUENTE: DAES/ONU. Los estimados para 2012 y 2013 son previsiones basadas en el Proyecto LINK.

Para la región latinoamericana también se ciernen nubarrones en 2012 y 2013, para la mayoría de loa países de América Latina y el Caribe el crecimiento económico se desaceleraría en 2012 y tendría cierta mejora en 2013, debido a la ralentización de la economía de China y la recaída en recesión en la Eurozona y EE. UU.

La desaceleración económica de Estados Unidos y Europa frenará el ritmo de crecimiento de las exportaciones, de las remesas del exterior y los ingresos relativos al sector turístico ${ }^{7}$. En especial para los países de América del Sur, la ralentización del crecimiento prevista se explica principalmente por el estancamiento en Europa y Estados Unidos, así como, la desaceleración de la economía China ${ }^{8}$, que impactaría en el volumen de la demanda externa y los precios internacionales de los productos básicos (commodities). Durante 2011 la mayoría de países de América del Sur, registraron un elevado crecimiento económico (ver, Cuadro 2), debido a los boyantes precios internacionales de las materias primas que contribuyeron al crecimien- to económico de los países exportadores de dichos bienes. Los exportadores de metales y minerales, como Chile y Perú, fueron los más beneficiados, seguidos por los exportadores de petróleo y gas como Venezuela, Colombia, Ecuador y Bolivia, así como por los exportadores de productos agrícolas como Argentina, Brasil, Chile, Paraguay y Uruguay. Sin embargo, a finales de año las economías de Argentina, Chile y Perú fueron perdiendo vigor ante la experimentación de caídas de los precios internacionales de sus productos de exportación.

El crecimiento económico de la región en 2012 y 2013 (ver, Cuadro 2) se proyecta debido a los supuestos que los ingresos derivados de los términos de intercambio se mantendrían en niveles elevados, aunque en la mayoría de los países deberían disminuir debido a los menores precio promedio de las materias primas. Asimismo, al dinamismo de los ingresos por concepto de remesas de los trabajadores latinoamericanos emigrados, a la sostenida expansión del crédito al sector privado y a la mejora de los indicadores laborales que sigue observándose en las eco-

$7 \quad$ Factores de crecimiento muy importantes para América Latina y el Caribe.

8 China es un gran comprador de materias primas e inversionista clave para la subregión. 
Cuadro 2

Principales Países de América Latina: Tasas de crecimiento del producto, 2009-2013

(Cambio porcentual anual)

\begin{tabular}{|c|c|c|c|c|c|}
\hline & 2009 & 2010 & 2011 & 2012 & 2013 \\
\hline América Latina y el Caribe & -2.1 & 6.0 & 4.3 & 3.3 & 4.2 \\
\hline Países integrados financieramente & & & & & \\
\hline Brasil & -0.6 & 7.5 & 3.7 & 2.7 & 3.8 \\
\hline Chile & -1.7 & 5.2 & 6.4 & 3.4 & 6.0 \\
\hline Colombia & 1.5 & 4.3 & 4.4 & 4.0 & 3.8 \\
\hline México & -6.3 & 5.8 & 3.8 & 2.5 & 3.6 \\
\hline Perú & 0.9 & 8.8 & 5.9 & 5.2 & 4.7 \\
\hline Paises Agroexportadores & & & & & \\
\hline Argentina & 0.9 & 9.2 & 7.6 & 7.2 & 7.2 \\
\hline Paraguay & -3.8 & 15.3 & 3.4 & 3.4 & 4.6 \\
\hline Uruguay & 2.6 & 8.5 & 5.1 & 3.4 & 2.8 \\
\hline Paises Exportad. de Hidrocarburos & & & & & \\
\hline Bolivia & 3.4 & 4.1 & 4.2 & 3.8 & 3.8 \\
\hline Ecuador & 0.4 & 3.2 & 5.0 & 3.6 & 3.8 \\
\hline Trinidad y Tobago & -3.5 & 2.5 & 1.7 & 4.4 & 4.5 \\
\hline Venezuela & -3.3 & -1.4 & 3.5 & 2.0 & 3.9 \\
\hline
\end{tabular}

FUENTE: DAES/ONU Y CEPAL

nomías de la región. Factores gracias a los cuales la demanda interna regional mantendría un elevado dinamismo, aunque crecería a tasas más moderadas.

$\mathrm{Si}$ bien se espera que el comercio de servicios se mantenga estable y las remesas muestren un aumento relativo en toda la región, sin embargo, esto no será suficiente para compensar la reducción del superávit comercial $^{9}$ y la consecuente acentuación del déficit en la cuenta corriente de la balanza de pagos, que podría ascender de 1.2 por ciento en 2011 hasta 1.7 por ciento del PIB regional en $2012^{10}$.

\section{PRINCIPALES CARACTERISTICAS DEL PROCESO DE LA CRISIS}

La economía mundial atraviesa una recesión aguda provocada por una crisis financiera masiva y una grave pérdida de confianza a partir del tercer trimestre de 2008. En efecto, las economías de todo el mundo se han visto seriamente afectadas por la crisis financiera y la desaceleración de la actividad económica de Estados Unidos, este país es el que más ha padecido las consecuencias de las crecientes tensiones financieras y el continuo enfriamiento del sector vivienda, pero Europa Occidental y las economías avanzadas de Asia, también, se han visto duramente perjudicadas por el colapso del comercio mundial ${ }^{11}$, así como, por el agravamiento de sus propios problemas financieros y las correcciones del sector inmobiliario en algunos países.

El veloz enfriamiento de la actividad mundial ha coincidido con una rápida disipación de las presiones inflacionarias. Los precios de las materias primas retrocedieron (durante 2009) considerablemente, respecto a los máximos registrado a mediado de 2008, lo cual causó ingente pérdida de ingresos a los países exportadores de commodities.

9 El superávit comercial regional disminuiría del 1.3 por ciento del PIB en 2011 a una tasa cercana a 0.7 por ciento en 2012.

10 Los países exportadores de hidrocarburos serían los únicos beneficiados al registrar un superávit comercial, debido al alza del precio de los combustibles.

11 En el 2009 el producto mundial decreció a -2.4 por ciento, mientras que el comercio mundial decreció más a -9.9 por ciento (ver, Cuadro 1). Dicha demanda ha tenido como contrapartida el crecimiento exportador y de demanda de inversión de algunos países en desarrollo, siendo China el caso más notable. Los déficits externos crecientes de EE. UU. Se financiaron con superávits comerciales de países como China y otros que habían acumulado grandes cantidades de reservas internacionales. 


\section{Génesis de la crisis y principales características.}

En el transcurso de setiembre y octubre de 2008 se experimentaron una intensificación de las turbulencias financieras que ponían de manifiesto el carácter sistémico de la crisis. El inicio de los problemas fue localizado en las grandes economías desarrolladas, basándose en gran parte, en una fuerte demanda de bienes de consumo en los Estados Unidos estimulada con crédito fácil y barato que generó alzas explosivas en los precios de las viviendas . Mientras tanto, la creciente des-regulación financiera junto con la proliferación de nuevos instrumentos financieros (títulos basados en hipotecas, obligaciones colaterizadas, etc.) fomentaron una acumulación masiva de activos financieros sustentada en crecientes niveles de deuda de hogares, corporaciones y gobiernos.

El crecimiento explosivo de la deuda fue posible al cambiar el modelo subyacente de estructura bancaria, del modelo tradicional de "comprar para tener" hacia el modelo comercial de "securitización" que se sustenta en "crear para intercambiar" con notable velocidad. En consecuencia, la razón de apalancamiento de algunas instituciones llegó a subir tanto como 30, muy por encima del techo de 10 que se impone generalmente en bancos de depósito tradicionales. La consecuencia fue un desapalancamiento violento que derrumbó a instituciones financieras de prestigio y causó una evaporación de la liquidez mundial.

Lo que siguió fue una disposición gigantesca de fondos públicos utilizados para recapitalizar los bancos, resultando en una apropiación (parcial o total) de las instituciones en problemas, así como, la provisión de avales gubernamentales sobre los depósitos bancarios $\mathrm{u}$ otros activos.
Las implicaciones para el comercio y las finanzas internacionales fueron la experimentación de una fuerte volatilidad de los precios de los bienes primarios; significando consecuencias de largo alcance para los países en desarrollo. Los precios de los bienes primarios estuvieron sujetos a una altísima volatilidad durante 2008, la mayoría de dichos precios se han mantenido fuertemente al alza en el primer semestre de 2008, continuando la tendencia que empezó en 2003. Pero desde mediados de 2008 el cambio de tendencia fue abrupto. Ej. Los precios del petróleo cayeron más de 60 por ciento. Los precios de otros bienes primarios como los granos cayeron de manera significativa, por lo que no se auguraron buenas perspectivas para el comercio internacional. El crecimiento del comercio internacional de 4.3 por ciento en 2008 experimentó una caída altamente significativa a -9.9 por ciento en 2009 .

\section{Principales acontecimientos durante 2010}

Durante 2010 se observó una frágil recuperación y desigual entre países. Las condiciones crediticias eran todavía restrictivas en las economías desarrolladas más grandes, en donde muchas instituciones financieras no habían consolidado aun el proceso de desapalancamiento y de limpieza de sus activos en sus balances.

Paralelamente, se dieron fuertes estímulos fiscales, fomentados por los gobiernos de un amplio número de países, así como, al reabastecimiento de inventarios en las industrias alrededor del mundo. A pesar de ello la demanda de consumo e inversión continuaron siendo débiles, debido principalmente al aumento del desempleo y del subempleo. 
El crecimiento global se situó por debajo del potencial, luego de la gran contracción ocurrida en 2009 (el producto mundial cayó en $-2.4 \%$ ), la primera ocurrida desde la Segunda guerra Mundial, el nivel de actividad económica mundial se situó alrededor del 4.0 por ciento en 2010 , por debajo de lo que habría podidos ser si la tendencia de crecimiento anterior a la crisis se hubiera mantenido (en el periodo 2005-2008 el producto creció, en promedio, 3.3 por ciento).

Por lo tanto, no se esperó que las principales economías desarrolladas provean un significativo ímpetu al crecimiento mundial en el corto plazo, debido, principalmente, a la demanda de consumo e inversión débiles, y a que las empresas tuvieron reticencia a invertir por las bajas tasas de utilización de la capacidad instalada y a una oferta de crédito insuficiente. Más aún se consideró que los impulsos generados por los estímulos de política económica y por las necesidades de reciclaje de inventarios disminuyeran con el tiempo.

El crecimiento en la mayoría de los países en desarrollo continuó dependiendo de las fluctuaciones del comercio internacional, así como de los precios de los productos básicos y de los flujos de capital. En las proyecciones para ese año se consideraron que las condiciones para el comercio y las finanzas internacionales continuaran siendo frágiles.

Se entendió que un re-equilibrio global sostenible no era tarea fácil y que requería de mecanismos más efectivos de cooperación internacional conformada por cuatro componentes: desarrollar consensos sobre objetivos comunes a través de consultas y mediaciones; afianzar los compromisos por medio de agendas aña a año con claras metas para los ajustes de política acordados; mejo- rar los medios para arbitrar mediaciones y para asegurar la legitimidad de los mediadores; e iniciar reformas sistémicas en el campo financiero y monetario internacional. En ese contexto, el marco propuesto por el G20 fue meramente declarativo.

\section{El panorama económico mundial en 2011}

Después de un año de recuperación frágil y desigual, el crecimiento económico mundial comenzó a desacelerarse a mediados de 2010. Dicha ralentización continuó en 2011 debido a las deficiencias en las principales economías desarrolladas que siguieron constituyendo un lastre para la recuperación global y plantearon riesgos para la estabilidad económica mundial en los próximos años.

La respuesta política a la crisis se debilitó durante 2010 debido a la ampliación de los déficits presupuestarios y al aumento de la deuda pública, que limitaron el apoyo para más estímulos fiscales. En consecuencia, el crecimiento de la producción global se ha desacelerado considerablemente durante el año 2011 (véase Cuadro 1, supra).

El rápido enfriamiento de las economías desarrolladas ha sido tanto causa como efecto de la crisis de deuda soberana en la zona del euro y, de los problemas fiscales en otros países. Los problemas de deuda pública en varios países de Europa empeoraron en 2011 y han acentuado las debilidades del sector bancario. A pesar del progreso alcanzado en dar de baja los activos en problemas del sector bancario, los riesgos siguen siendo múltiples. Los mercados de bienes raíces pueden deteriorarse aún más, el crecimiento del crédito continuo siendo débil en medio de un persistente desempleo elevado. Las políticas de dinero barato (bajas tasas de interés y fle- 
xibilidad cuantitativa) se han mantenido en la mayoría de los países con la intención de ayudar a los sectores financieros a retornar a la "normalidad" y estimular así la actividad económica. Esto, sin embargo, ha introducido nuevos riesgos, incluyendo una mayor volatilidad del tipo de cambio entre las principales monedas y un aumento de los flujos de capital volátiles a los países emergentes. Estos nuevos factores están creando tensiones que perjudican la coordinación de políticas a nivel internacional, así como los esfuerzos para enfrentar los desequilibrios de balanza de pagos.

La economía de Estados Unidos, que se levanta de la recesión más larga y profunda desde la Segunda Guerra Mundial, experimenta un ritmo de recuperación más débil de su historia. Aunque el nivel de su producto bruto interno alcanzó en 2011 el pico anterior a la crisis, una recuperación completa del empelo tardará al menos otros cuatro (4) años. El crecimiento en muchos países europeos también continuó siendo bajo y en algunos de ellos continuó la recesión debido a los drásticos recortes fiscales.

El crecimiento de los países en desarrollo también tendió a una moderación en el 2011. Los países en desarrollo continuaron impulsando la recuperación mundial a pesar del desaceleramiento del crecimiento de la producción. Los países asiáticos continuaron, en el 2011, mostrando un fuerte crecimiento. De hecho, el vigoroso crecimiento de las principales economías en desarrollo, especialmente China, ha sido factor importante en la recuperación del comercio mundial y de los precios de los bienes primarios, que es beneficiosa para el crecimiento en América Latina, la Comunidad de Estados Independientes y parte de África. Sin embar- go, la recuperación económica se mantiene por debajo del potencial en las tres regiones.

Las tendencias del comercio mundial han sido opuestas, mientras que el volumen de las exportaciones de muchas economías emergentes ha alcanzado, a veces con creces, los picos anteriores a las crisis, las exportaciones delos países desarrollados no se ha recuperado totalmente. El comercio mundial creció a un ritmo del 6.6. por ciento, luego de una fuerte expansión durante 2010 (12.8\%), por lo se prevé crezca en el 2010 un 4.4 por ciento (véase Cuadro 1, supra).

A pesare de la recuperación gradual de los dos últimos años, los valores de las importaciones de las tres grandes economías desarrolladas se encuentran aún muy por debajo de los picos observados antes de la crisis. Asimismo, se observa que la recuperación de las exportaciones de estas economías desarrolladas refleja un rápido crecimiento de las importaciones de los países de Asia Oriental y América Latina. Sin embargo, la interrogante que surge es sí las economías emergentes pueden seguir actuando como motores del crecimiento del comercio mundial.

\section{RIESGOS E INCERTIDUMBRE}

Dada la fragilidad de la economía mundial, el escenario base para 2012 y 2013 están sujetas a un alto grado de incertidumbre. Los riesgos se inclinan hacia la baja e incluyen una escalada de la crisis de la deuda en la zona del euro, así como la subida de los precios mundiales de la energía debido al incremento de las tensiones políticas en el medio oriente.

Las perspectivas negativas surgieron a mediados de 2011, cuando los mercados mostraron una creciente incertidumbre respecto de la evolución de la economía global, 
relacionada sobre todo con las crisis soberanas de algunos países de la zona del euro ${ }^{12}$ (véase, supra), y en menor grado, con el bajo crecimiento y manejo macroeconómico de la economía estadounidense, así como las dudas sobre la capacidad de las economías asiáticas de poder compensar la ralentización del crecimiento en esas regiones.

Bajo un panorama de creciente volatilidad de los mercados financieros internacionales con respecto al desenlace de la crisis de la deuda soberana en Europa ${ }^{13}$, se atenuaron los flujos de capital hacia América Latina como reflejo de la fuga en busca de mayor calidad y aumentaros las primas de riesgo. $\mathrm{Al}$ mismo tiempo se invirtieron las tendencias de apreciación cambiaria. En ese contexto, los procesos reflejan el hecho de que las economías de la región no serían ajenas a un enfriamiento acentuado de la economía mundial y que los bonos estadounidenses se perciben aún como la inversión de menor riesgo.

El futuro incierto de la deuda ha exacerbado el recurso de consolidación fiscal, cuya orientación contractiva ha deteriorado las expectativas de crecimiento futuro. Ello ha traído aparejado un debilitamiento de los niveles de actividad, con contracciones económicas, lo que ha reducido los ingresos fiscales y aumentado la necesidad de financiamiento, agravándose así aún más la crisis de la deuda. Esta dinámica ha llegado a afectar la confianza en economías que antes de la crisis exhibían niveles de deuda pública aparentemente sostenibles y una alta calificación crediticia. El resultado ha sido alzas en las primas de riesgo, que durante 2010 exhibieron una tendencia al alza pero con oscilaciones, es decir, experimentaron a partir de mediados de 2011 aumentos muy pronunciados, incluso en Alemania, con lo que se encareció significativamente la deuda pública y se dificultó, en gran medida, la estabilización de las posiciones fiscales en países con problemas de sostenibilidad e importancia sistémica (Italia y España).

Por otro lado, como se afirmó (supra), Estados Unidos, no ha podido superar los problemas en su sector inmobiliario y financiero, además, continua sufriendo de un desempleo persistentemente alto, y no ha llegado a un acuerdo sobre los lineamientos de su política fiscal, lo que implicó un impacto fiscal contractivo, de manera que su crecimiento se desaceleró marcadamente respecto al periodo de pre-crisis.

En la otra parte del mundo, el dinamismo de las economías emergentes de Asia no fue suficiente para contrarrestar la ralentización de las economías desarrolladas, por lo que los estimados para su crecimiento para el presente año es de bajo crecimiento. Todo ello, a pesar que el crecimiento en China fue robusto en 2011 (véase, supra), sin embargo ya registraba una tendencia hacia la desaceleración, debido al retiro de estímulos a la inversión y el control monetario y crediticio ante las alzas de la inflación. A inicios de 2012 , los indicios de un enfriamiento mayor de su economía llevó a sus autoridades a tomar medidas para estimular la demanda interna. En cambio, la economía de India mantuvo su dinamismo en 2011, en que registró

12 La incertidumbre en torno a qué parte de los costos de reducción de la deuda soberana serán absorbidos por los bancos de esa región, han exacerbado el recurso a la consolidación fiscal, cuya orientación contractiva ha deteriorado las expectativas de crecimiento futuro de la eurozona.

13 Ante la ausencia de un plan dotado con suficientes recursos, se incrementó la probabilidad de una salida desordenada de la crisis, situación en que los Estados se verían forzados a hacerse cargo de las pérdidas de sus sistemas financieros ante una declaración de insolvencia de algún país de la eurozona. Sí no lo hiciesen, a la crisis de la deuda se agregaría una crisis bancaria. 
un crecimiento del 7.7 por ciento, de la mano de la inversión y el consumo privado; en este caso, el aumento de los niveles inflacionarios ha sido la principal amenaza para la continuidad de ese ritmo de crecimiento.

Estados Unidos y la Unión Europea constituyen las dos economías más grandes del mundo y sus actividades económicas están intrínsecamente ligadas. Sus dificultades actuales ${ }^{14}$ repercuten de una a otra con el potencial de ocasionar otra recesión global. Los países en desarrollo, que se habían recuperado fuertemente de la recesión mundial de 2009 , se verían también afectados a través de los canales comerciales y financieros.

Para enfrentar la crisis y que los pronósticos cuantitativos se cumplan se requiere de una coordinación internacional más decisiva de medidas de estímulo adicionales en todos los países, con énfasis en la creación de empleo, más inversión en infraestructura, mayor eficiencia energética y su sostenibilidad y, la seguridad alimentaria. Urge la coordinación internacional en dichas políticas para implementar las reformas estructurales en el mediano plazo.

En el caso de los países de América latina se debe tomar en cuenta una gama más o menos completa de herramientas para contener los posibles efectos inmediatos de la crisis para sus economías y aplicar políticas contra cíclicas que moderen las consecuencias relativas del crecimiento, el empleo y el nivel de vida. Es decir, la región cuenta en general con suficiente espacio fiscal para aplicar una política contra cíclica. Existen diversas formas de operacionalizar el concepto de espacio u holgura fiscal, que suelen relacionarse con la capacidad de incrementar en forma solvente el gasto.

Sobre la base de la experiencia acumulada en la aplicación en varios países de políticas destinadas a contener el impacto de la crisis de 2008-2009, se podría aprovechar el espacio fiscal para implementar políticas orientadas a minimizar las consecuencias laborales de una nueva crisis. Los países podrían recurrir transitoriamente a esquemas de subsidios para evitar los despidos y a la creación o ampliación de programas de empleo de emergencia, que suelen ser una fuente de ingresos, sobre todo para los trabajadores menos calificados. En suma, si bien un escenario externo más adverso al previsto afectaría a las economías de la región, en varios casos se dan las condiciones necesarias para tomar medidas contra cíclicas que moderen sus consecuencias en términos de crecimiento, sin afectar la sostenibilidad de las finanzas públicas y externas. Asimismo, la significativa acumulación de reservas internacionales en la gran mayoría de países de la región permitiría atender la demanda de liquidez en divisas y la experiencia adquiri$\mathrm{da}$, permite suponer que los bancos centrales están en condiciones de suplir también la liquidez en moneda nacional.

Entre los riesgos que puede enfrentar la región latinoamericana, se encuentra la posibilidad de un escenario externo adverso, que se traduzca en una agudización de la crisis de los sistemas financieros y de la deuda soberana de los países de mayor tamaño relativo de la zona del euro (España e Italia). Dada la experiencia de las crisis financieras anteriores, especialmente la del 2008, esto podría

14 La austeridad fiscal es parte del problema. las tajantes medidas de austeridad fiscal que vienen siendo implementadas en países desarrollados como respuesta a déficits y niveles de deuda altos tienden a debilitar aún más el crecimiento y las perspectivas de empleo, complicando efectivamente el ajuste fiscal y la reparación de balances del sector financiero (la crisis de deuda soberana se agravó dando lugar a un mayor debilitamiento de los balances de los bancos con deuda soberana entre su patrimonio). 
suponer una "fuga de capitales" en busca de calidad y seguridad, que se expresaría en una interrupción de su afluencia hacia la región, el retiro de depósitos e inversiones de cartera y la suspensión de líneas de crédito bancarias en el exterior, lo que produciría caídas de los mercados de valores y una depreciación de las monedas.

Por lo que los precios de los bienes primarios que exporta la región disminuirían y lo volúmenes exportables también se verían afectados, tanto por la menor demanda proveniente de Europa como por sus repercusiones a nivel de actividad de los demás mercados de importancia para el comercio exterior de la región (EE. UU. Y Asia).

En este análisis también se considera la situación regional y los efectos en el plano interno de cada economía, así los ingresos públicos de los países exportadores netos de productos básicos se verían afectados, mientras que los ingresos tributarios de los exportadores netos por concepto de aranceles e impuestos al valor agregado podrían reducirse a causa de los menores precios y el menor valor de las importaciones. En ambos casos, los resultados fiscales mostrarían un claro deterioro.

En resumen, para evitar una nueva recesión global hay la necesidad de abordar las cuatro grandes debilidades de las economías de manera simultánea, con los consiguientes cambios de política fundamentales, tales como:

- Coordinar las políticas fiscales tendientes a proporcionar nuevos estímulos a corto plazo, focalizados en la sostenibilidad fiscal a mediano plazo;

- Rediseñar la política fiscal y alinearlos con las políticas estructurales para la creación de empleo y el crecimiento económico;
- Coordinar las políticas monetarias para frenar la expansión de la moneda y la volatilidad de los capitales, y acelerar la reforma de la regulación financiera para hacer frente a la fragilidad financiera; $y$

- Garantizar la financiación para el desarrollo adecuado (sostenible).

\section{REFERENCIAS BIBLIOGRÁFICAS}

1. Balance Preliminar de las Economía de América Latina y el Caribe 2009, Cepal, Santiago de Chile, Diciembre 2009.

2. Balance Preliminar de las Economías de América Latina y el Caribe 2010, Cepal, Santiago de Chile, Diciembre 2010.

3. Balance Preliminar de las Economías de América Latina y el Caribe 2011, Cepal, Santiago de Chile, Diciembre 2011.

4. Cielos Oscurecidos por la Economía Mundial. WESP/ONU Update per Mid2012, New York, June 2012.

5. Crisis. Perspectiva del Empleo y Comercio, Herrera García, Beatriz, (doc. inédito), Lima 2011.

6. Global Financial Stability Report (GFSR), Informe anual del FMI, Washington, 2009.

7. Global Economic Outlook, Chapter I. Global Economic Outlook. Prospects for the World Economy in 2012-2013, United Nations, New York, 2011.

8. Informe Macroeconómico de América Latina y el Caribe, Cepal, Santiago de Chile, Junio 2012.

9. Perspectivas de la Economía Mundial, Informe Anual del FMI, Washington, Abril de 2009.

10. Situación y Perspectivas para la Economía Mundial 2012, Naciones Unidas, New York, January 2012. 
A CUATRO AÑOS DE CRISIS MUNDIAL CONTINÚAN SERIOS NUBARRONES

11. World Economic Situation and Prospects (WESP) 2009, DESA/ONU, New York, December 2008.

12. World Economic Situation and Prospects (WESP) 2010, DESA/ONU, New York, December 2009.
13. World Economic Situation and Prospects (WESP) 2011, DESA/ONU, New York, December 2010.

14. World Economic Situation and Prospects (WESP) 2012, DESA/ONU, New York, December 2011. 